tests. In the grading of raw milk a considerable proportion of samples are classified differently by the methylene blue test prescribed by the Ministry of Health and the routine resazurin test adopted provisionally by the Ministry of Agriculture, and further work on this problem is necessary. The complete reduction of resazurin has been shown to be generally slower than that of mothylene blue in poor quality milk, but in the majority of samples with a good keeping quality it is similar or quicker. A study of the influence on dye tests of cells from the cow's udder has indicated that the amount of winter market milk which is reduced in grade owing to mastitis and late lactation is 4 per cent when the methylene blue test is used and about 10 per cent when the standard resazurin test is employed.

One of the papers on mastitis of the cow suggested the use of the Hotis test in routine laboratory diagnosis. After twenty hours incubation any samples which give a positive reaction are plated. This method, which economizes materials and labour, appears to be equal in reliability to direct plating.

A paper on the bacteriological aspects of blood transfusion discussed problems arising in the storage of blood and the production of plasma, and described methods of ensuring freedom from contaminating organisms. An account was given of the contaminants encountered in practice and of their action on blood and plasma.

The subjects discussed at this meeting of the Society show that problems in applied bacteriology which are largely related to war-time conditions are occupying the attention of the members. The dominant interest is in dairying, an indication of the national importance of milk and its products.

Copies of the Society's Proceedings containing the full papers can be purchased from the Hon. Treasurer, L. J. Meanwell, United Dairies, Ltd., Ellesmere, Salop.

\section{MEASUREMENT OF HEARING AND DEAFNESS}

$\mathrm{A}^{\mathrm{N}}$ N article by M. B. Gardner (Bell Lab. Rec., 22, No. 1 ; September, 1943) gives the results of tests carried out to determine hearing ability. Audiometers for measuring hearing loss vary considerably in arrangement, depending on how they are to be used and on how extensive a test is to be made. One of the models which has been widely used is the $2 A$ audiomster minufactured by the Western Electric Company. It includes an adjustable oscillator as a source of single-frequency tones and an attenuator by which the intensity level of the tone may be varied. The person whose hearing is being tested listens to the tone through a small receiver, and is given a push-button with which he lights or extinguishes a lamp in front of the operator. Normal procedure is to have the lamp lighted as long as the tone is heard, and the patient extinguishes the lamp by releasing the push-button when the tone disappears.

Eight frequencies are provided from 64 to 8,192 cycles, which covers the important range of hearing, and the frequencies are selected as desired by keys on the audiometer. The output circuits for the various frequencies are so arranged that with the attenuator dial set to the point marked zero loss, the output of the receiver is at an intensity corresponding to the threshold of the average ear for that frequency. At this position of the dial the attenuator is inserting nearly its maximum loss - a small amount of additional loss being provided to enable measurements to be made on those who hear somewhat better than the average. The dial is graduated in $5 \mathrm{db}$. steps. Normal procedure is to set the dial at a level that the patient can certainly hear, and then to reduce it step by step until the tone is no longer audible. The reading of the dial at the last step the patient hears gives his hearing loss at that frequency.

The intensities corresponding to the zero settings of the $2 A$ audiometer, which represent the threshold of hearing for audiometric purposes, were obtained from tests on a group of people of normal hearing between the ages of twenty and thirty. They are on the average 10-15db. higher than the minimum audible pressure values given in an earlier article*. The objective of these values was to determine the minimum pressures that can be heard by the human ear, rather than the pressures heard under normal conditions by a more average group of people. That the values used by the $2 A$ audiometer are well suited to their purpose is indicated by results obtained at the World's Fair in 1939. The threshold values of the $2 A$ audiometer correspond very closely to those found during this survey.

Although the threshold curve is of fundamental importance in all acoustical work, there is another curve that is of interest, and that at times becomes of critical importance. As the level of a sound is increased above the threshold, the sound becomes louder and louder until the response becomes more that of the sense of feeling. The stimulus is felt rather than heard, and at somewhat higher levels becomes painful. A curve drawn through these pressures, at which the response is one of feeling as well as hearing gives the so-called threshold of feeling, and marks an upper limit to audible pressures. The area between these two thresholds represents the range of audible sound pressures, and by plotting the results of audiometer measurements on such a field, it is possible to gauge at a glance the relative seriousness of any particular pattern of hearing loss. Charts indicating these two thresholds are usually employed when plotting hearing losses but, on them, the threshold of hearing is represented by a horizontal line near the top, and the threshold of feeling is plotted in decibels relative to the threshold of hearing.

Deafness may be due either to a transmission loss in the three bones of the middle ear, or to a reduced response of the auditory nerves. The former is called 'conductive deafness', and the latter 'nerve deafness'. With nerve deafness the loss usually increases at the higher frequencies. With conductive deafness, on the other hand, the loss is more constant with frequency, and may even beless at the higher frequencies. In addition, both forms of loss may be present, giving what is called mixed deafness. Even when it is not clear from the audiogram which form of deafness is predominant, the two types of deafness may be distinguished by other criteria. As a result of the lack of sensitiveness of the responding system that results from nerve deafness, no response is obtained until the stimulus reaches a certain value. Beyond this value, however, the response increases rapidly with the stimulus; so rapidly, in fact, that at high intensity levels individuals having one normal ear and one nerve-deafened ear judge the sound to be equally loud in either ear. With conductive deafness all sounds, of whatever level, suffer the same loss. The deafened person therefore hears more nearly

*Bell Lab. Rec., 21, No. 10 (1943) ; see NATURE, 152 (Oct. 16, 1943). 
like the normal individual, except that all sounds are reduced in intensity. Such an individual is not nearly so apt to complain of someone shouting too loudly as would the individual who has become affected by nerve deafness.

Those tested were asked to indicate their hearing ability according to five classes: (1) no noticeable difficulty in hearing; (2) unable to understand speech in public places such as churches or theatres; (3) unable to understand speech from a person two or three feet away; (4) unable to understand speech from a telephone; and (5) unable to understand speech under any condition. Their audiograms were then taken and recorded. Such tests were made on some 9,000 persons, and the audiograms of those of each of the five classes were then averaged to discover the amount and type of loss that was responsible for the various inabilities to hear. These results show, in a graph, that the five classes of loss are separated on the average by about $20 \mathrm{db}$. For those reporting normal hearing, the average loss was about $5 \mathrm{db}$., while for the other four classes it was $25,45,65$, and $85 \mathrm{db}$., respectively, the latter figure corresponding to total deafness for speech.

\section{STATISTICAL METHODS FOR GOVERNMENT DEPARTMENTS}

$\mathrm{T}$ HE "Memorandum on Offieial Statistics" issued by the Council of the Royal Statistical Society is a notable document, not merely for its recommendations for the post-war period, but also for the lucid and concise analysis of the pre-war period and the developments in war-time. The analysis of the prewar period reflects little credit on the organization and method of the Civil Service. Each department collected its own statistics, and inadequate use was made even of the information available. The utilization of statistical material was imperfect and unsystematic, with loss of information and efficiency. No attempt was made to correlate the information with material available in other branches or departments. In only a few of the major departments was there any statistical organization which could be regarded as adequate. The staffing of departments was unsatisfactory in regard to the training of personnel and in certain respects to their status. Nowhere was a knowledge of statistical theory regarded as a necessary qualification for employment in statistical work, and the technical post of 'statistician' was practically unrecognized.

While the committee of the Royal Statistical Society which prepared the Memorandum is of opinion that in the pre-war period a good deal more could have been done by way of the analysis and interpretation of existing material, with great benefit to departments and to Ministers, it recommends that the collection of statistical material should continue, where possible, to be left to those departments and their branches the administrative duties of which bring them into daily contact with persons providing the information, so as to utilize the fund of experience acquired by administrative branches and the friendly relations which many of them have built up with their clientele. The branches may require advice from a co-ordinating statistical branch in the formulation of inquiries and the treatment of results, but the Memorandum is emphatic that the Central Statistical Office which is proposed to effect firm co-ordination of the statistical work of different departments should not relieve departments of their responsibility for collecting and compiling statistical data. Divorced so far as possible from routine analysis and from administration, it should be charged with the duty of preparing statistics required by the Government, such as the Budget White Paper, by Royal Commissions and by special committees appointed by the Government. It should ensure that as much statistical material as possible is made available to the public, and that all Government statistics are issued with the minimum of delay. It should endeavour to fill gaps in statistical information by advising departments on the desirability of certain lines of inquiry and should undertake research work or loan staff to assist other departments in undertaking such work.

Acting generally as a co-ordinating body, particularly through a small committee selected from the heads of statistical branches in the major departments, the Central Statistical Office should be responsible for the issue of the Statistical Abstracts for the United Kingdom and the "Guide to Current Official Statistics". It is suggested that the Office should also be responsible for the publication of a monthly bulletin of statistics on the lines of the Survey of Current Business issued by the United States Department of Commerce.

These are the principles on which the Memorandum considers the Central Statistical Office set up in 1941 should be reorganized after the War. The effect of the War has in fact been almost universally beneficial to statistics. The shortage of trained statisticians emphasizes the importance of the contribution they can make to the service of the State in the field of both descriptive and mathematical statistics. Some degree of internal training of the employees of statistical branches has been initiated, and increased use is being made of scientific aids to numerical work. There are also signs of a considerable change for the better in the public and departmental attitude towards statistics.

On the fundamental assumption that plans for reconstruction and for social reform will involve an increasing demand for comprehensive statistical information by the Government during the post-war reconstruction period and beyond, the Memorandum makes further recommendations. First, every major department should have a statistical branch under the direction of an administrative officer, and minor departments should either have a smaller unit or work under the guidance of the statistical branch in a major department or of the Central Statistical Office. Next, in regard to staff, certain statistical posts should be of grades equivalent to that of the more senior administrative officers, and the administrative personnel of statistical branches should be recruited from persons with mathematical or statistical qualifications; transfer ketween departments should be permitted where necessary. An endeavour should be made to post selected junior administrative officers to the statistical branch as part of their training, and technical posts of statistician created where departments consider them necessary. Full opportunity should be given for a technical statistician who showed administrative ability to be transferred to the administrative grade. The system of giving free courses in statistics to selected members of statistical branches should be extended and facilities given for advanced study. Opportunity should be given for members of statistical 